\title{
Adoption of Discovery Learning in Sharia Accounting Course
}

\author{
Vima Tista Putriana ${ }^{1}$, Dian Yuni Anggaraini ${ }^{2}$ \\ \{vimaputriana@eb.unand.ac.id ${ }^{1}$, dianyuni12@gmail.com ${ }^{2}$ \} \\ ${ }^{1,2}$ Accounting Department, Universitas Andalas, Padang, Indonesia
}

\begin{abstract}
This paper aims to evaluate discovery learning technique adopted in sharia accounting course offered. The research was conducted from January- June 2019 at one of three parallel classes for sharia accounting course offered by the Department of Accounting as an optional course for students sitting at the fourth semester. The finding of the research suggests that given the specificity of the course - integration between sharia and accounting fields, it might be better for the inductive technique of learning such as discovery learning is combined with other techniques such as case study- based learning, project-based learning and the conventional lecturing technique can be maintained to certain degree. Element of discovery learning is useful to stimulate students' activeness in learning process. Case study-based learning will help improve their understanding in terms of calculations and technical accounting of different business contract models known in Islam. Hence, project-based learning helps students to deepen their understanding on the topic of their interest. Finally, maintain a conventional lecturing technique to a certain degree is important as the course contains element of sharia. Sharia principles and concepts are supposed to be taught by instructor in order to avoid misunderstanding of the basic concepts and principles, what allowed and not allowed according to sharia.
\end{abstract}

Keywords: Discovery Learning, Sharia Accounting, Challenges, Implementation

\section{Introduction}

The current challenges facing university graduates are different from the past. The teaching approach used at the university therefore needs to adapt with the current changes. As noted by [1], the current university graduates should have three qualities: (i) have ability to solve problem (ii) easily adapt to change (iii) able to look at what they are doing and find ways to do it better. University graduates therefore need to acquire, interpret and evaluate data to learn, reason and solve problems. The learning model that can produce graduates with such qualities is more to inductive model instead of deductive one.

This paper aims to evaluate the implementation of discovery learning adoption - one of inductive learning technique in a particular course (i.e. sharia accounting - an optional course) offered for students majoring in accounting at the faculty of economics of Andalas University. The course aims to introduce concepts, principles and techniques of accounting implemented 
in sharia or Islamic-based institutions. The technique was first implemented during the last academic year of 2018/2019 to one of parallel classes (i.e. IV/A2). Results of around six months class observation and then supplemented by a survey distributed to the students in the last meeting indicate that learning process will be more effective if discovery learning technique is integrated with other techniques such as case study-based learning and projectbased learning. Moreover, conventional lecturing model needs to be maintained to a certain degree, given the nature of the course that involves element of sharia. Case study-based learning is needed to help students improve their skills related to technical accounting of various business contracts recognized by sharia and calculations involved.

The rest of the paper will be structured as follows. The next section will review relevant literatures on the topic of learning models and techniques. Next section will be methodology, followed by presentation of research results. Finally, discussion and conclusion.

\section{Literature Review}

There is growing interest in students-centered learning in higher education [2]. The interest was driven by the needs to prepare university graduates with some new qualities mentioned in the introduction part. The reason of why students-centered learning is able to produce university graduates with such necessary qualities is because the learning model that is inductive in nature encourages students to adopt a deep approach to learning [3], [4], [5]. Students-centered learning come in many forms, including discovery learning, inquiry-based learning, problem-based learning, project-based learning, and case-based teaching. The next discussion is focused on a specific form - discovery learning.

The first characteristic of discovery learning is that students are active. More clearly, students are actively seeking new knowledge as learning is not defined as simply absorbing what is being said or read. 'Students are engaged in hands-on activities that are real problems needing solutions'. Thus, students have a reason to find answers and to learn more. Hence, the focus in discovery learning is the process - how the content is learned not the end product. In other words, technique of discovery learning places 'learning how to analyze and interpret information to understand what is being learned rather' as more important than just giving the correct answer from rote memorization. Discovery learning pushes students to a deeper level of understanding because process-oriented learning can be applied to many different topics instead of producing one correct answer to match one question. This means that discovery learning emphasizes a mastery and application of overarching skills [1].

Thirdly, failure is not a bad thing in discovery learning because learning occurs even through failure just as what experienced by the famous case of Thomas Edison who has tried 1,200 designs for light bulbs until he found the right design. Thus, failure allows students to learn something new. Next, it is crucial that students receive feedback in the learning process when adopting discovery learning. Discussion of the topic with other students enhances and deepens student learning and makes it more permanent. Finally, internalization of concepts takes place when students go through a natural progression to understand them [1].

Discovery learning has three main attributes as noted by Bicknell-Holmes [6] and cited in Castronova [1] (i) Students create, integrate, and generalize knowledge through exploration and problem solving (ii) Student driven, interest-based activities which the student determines the sequence and frequency and (iii) activities to encourage integration of new knowledge into the learner's existing knowledge base. There are five major differences between discovery learning and traditional learning: learning is active rather than passive, learning is process- 
based rather than fact-based, failure is important, feedback is necessary, and understanding is deeper [3], [7], [8].

\section{Methodology}

To find out whether discovery learning technique can help achieve expected learning outcomes set for sharia accounting course, discovery learning was experimented at one of three classes of sharia accounting course in the academic year of 2018/2018. The technique was experimented in a regular class consisted of 25 students (class IV/A2). The justification to select this class was that the class was taught by one lecturer for the whole semester whereas the other two classes had two lecturers in charge. Thus, the reason was a practical reason easy to administer the research. The students were informed in the first meeting that the course would be delivered through discovery learning. They were given an explanation regarding of what discovery learning is and the roles expected from students and the lecturer.

Students were divided into several groups consisted of around five students. Each group should prepare a weekly assignment on the given topic. Students were informed the main sources to be used for each topic. However, they were advised to look for additional trusted sources themselves. The main sources were sometimes provided. Students wrote 10-20 pages of group assignment every week. One group presented their work during the class meeting and other students listened to the presentation, asked questions or clarifications.

Students were also asked to undertake an individual project to be completed by the end of semester. Students were given three topics that they could select in what topic they wanted to work on. The project required students to conduct a mini research - collecting primary data to small number of research participants (5-10 participants). Students wrote the research report and submitted it before the final exam.

During the last meeting, questionnaires were distributed to students to find out students' opinions regarding the learning technique that had been experimented. The questionnaire had ten questions with alternative answers as follows: 'strongly agree', 'agree', 'neutral', 'disagree' and 'strongly disagree' and three open-ended questions. Data from the survey were analyzed using descriptive statistics such as frequency and tabulation.

The first step of analysis was to tabulate students' responses for each question. This first step of analysis provided a raw data how many students answered 'strongly agree', 'agree', 'neutral', 'disagree' or 'disagree' for each question or a given statement. The next step of analysis was to re-define the responses: 'strongly agree' to 'agree' and 'strongly disagree' to 'agree'. 'Neutral' can be assumed to be 'disagree'. Therefore, students' responses fall into two categories only: 'agree' and 'disagree'.

\section{Results}

Students' responses on Q1 that asked students' opinion whether discovery learning is suitable for sharia accounting course are as follows: strongly agree (12\%), agree (40\%), neutral (20\%), disagree (25\%) and strongly disagree (20\%). After reclassification of students' responses, the result is shown in diagram below: 


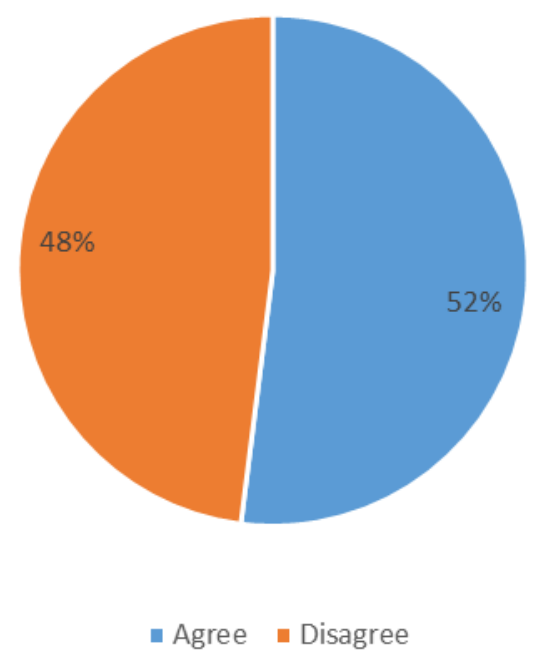

Figure 1. Students' Responses on Q1 (Discovery learning is a suitable learning technique to be applied for studying sharia accounting course)

Figure 1 indicates that adoption of discovery learning technique to deliver sharia accounting course was supported by over $50 \%$ of students. $48 \%$ of students thought that the conventional lecturing method would be better.

The moderate students' support for the adoption of the discovery learning technique was strengthened with the result for Q2 that seeks students' opinion whether 'Discovery learning should be continued'. Figure 2 shows that proportion of students who agreed for the technique to be continued is even slightly lower than the ones who disagreed.

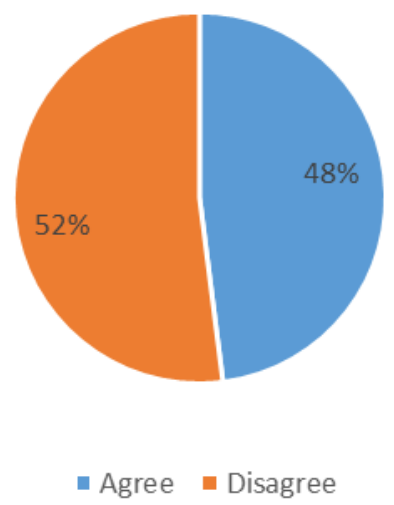

Figure 2. Students' Responses on Q2 (Discovery Learning Should be Continued)

The moderate support for the discovery learning adoption for the sharia accounting course can be connected to the inherent weaknesses of the discovery learning and some implementation barriers that students' responses on two open-ended questions (Q12 and Q13) have revealed. These will be discussed further later. 
Despite from the moderate support of students for discovery learning, students however acknowledges benefits of discovery learning gained. Students for instance felt that the technique had stimulated their motivation to further explore topics on their interests (see Figure 3).

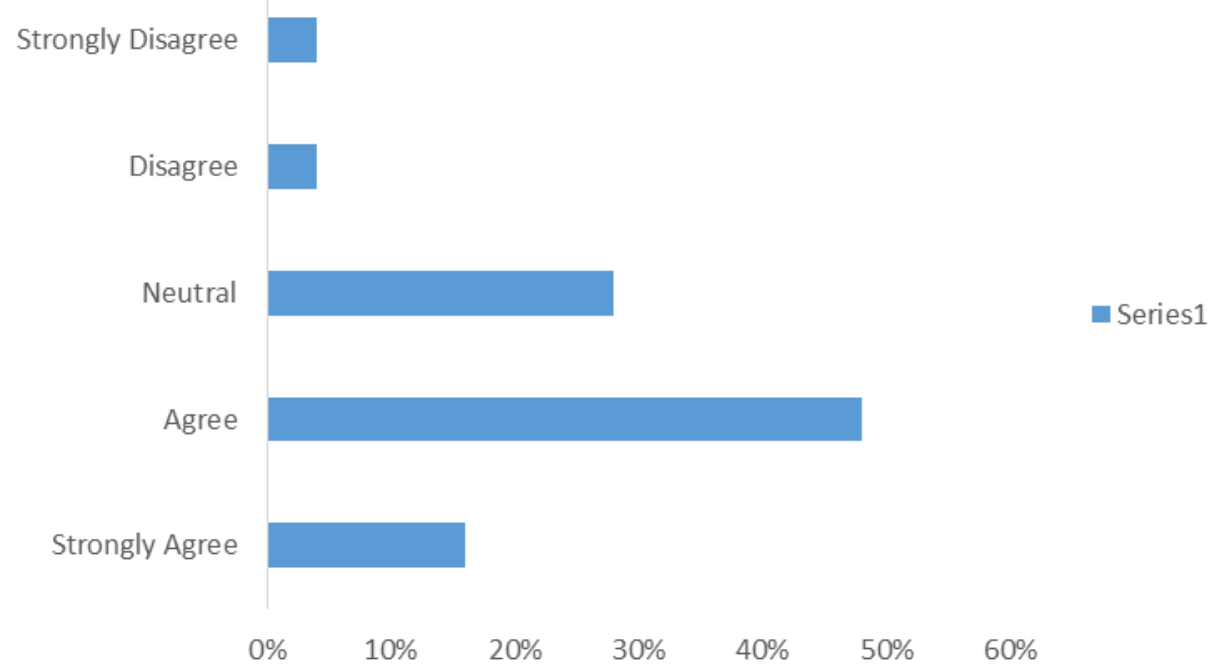

Figure 3. Students' Responses on Q3 (Discovery learning stimulates motivation to Further Explore topics on my interests)

As shown in Figure 3 above, almost $20 \%$ of students strongly agreed and almost $50 \%$ of students agreed that they were motivated to expand their learning on the topics. This is something positive compared to if the conventional lecturing method was implemented. Moreover, over $60 \%$ of students also said that adoption of discovery learning had made them creative in searching for course materials (see Figure 4) and over $60 \%$ of students said that they had become an active learner (see Figure 5).

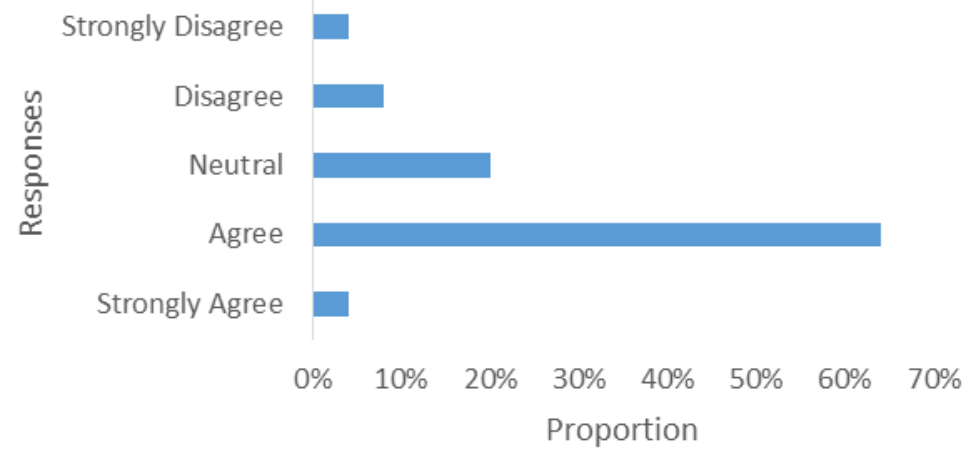

Figure 4. Students' Responses on Q4 (Discovery Learning encourage learning creativity) 


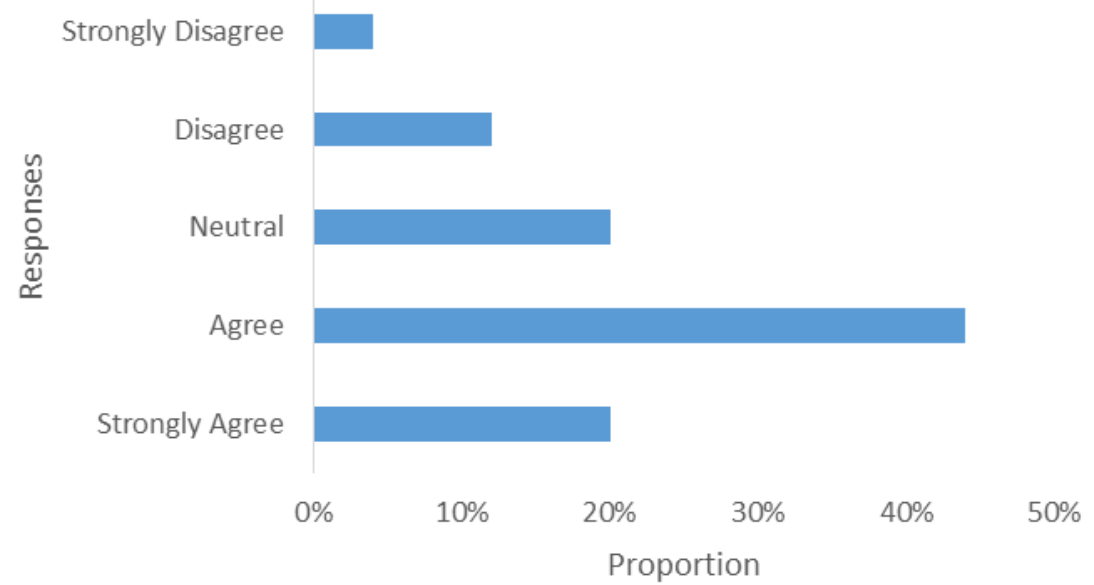

Figure 5. Students' Responses on Q5 (Discovery Learning encourages me to be an active learner)

When asked about whether discovery learning promotes cooperation among students both in with a group and among groups, majority of students agreed that the technique has a positive impact on students' cooperation (see Figure 6 and 7).

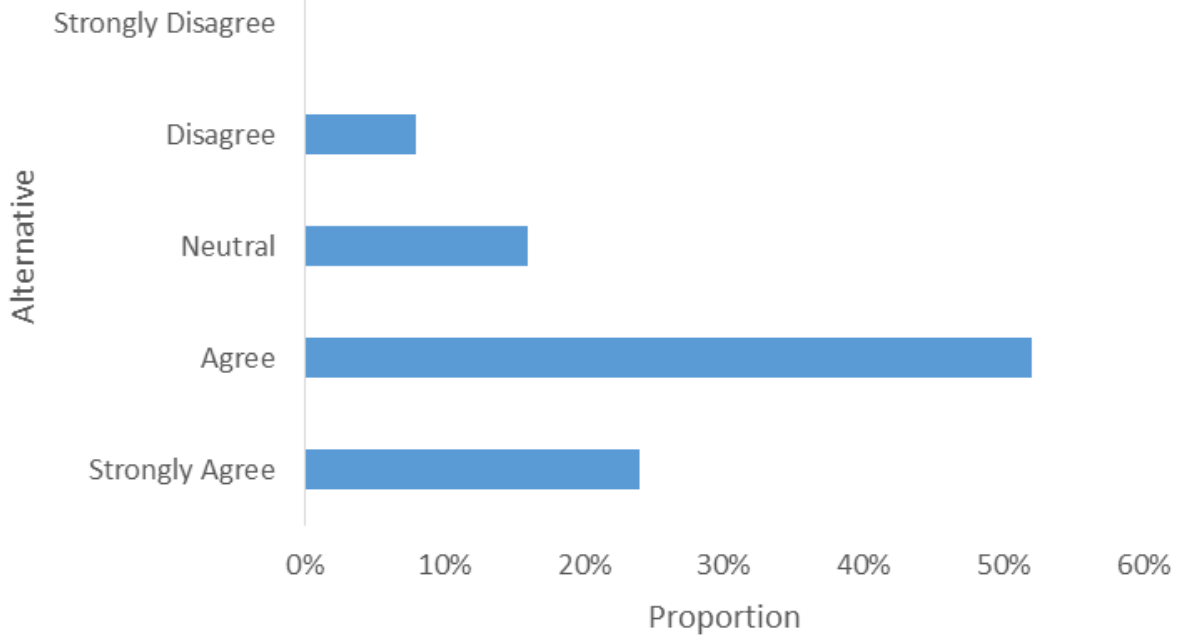

Figure 6. Students' Responses on Q7 (Discovery Learning encourages cooperation among students in one group) 


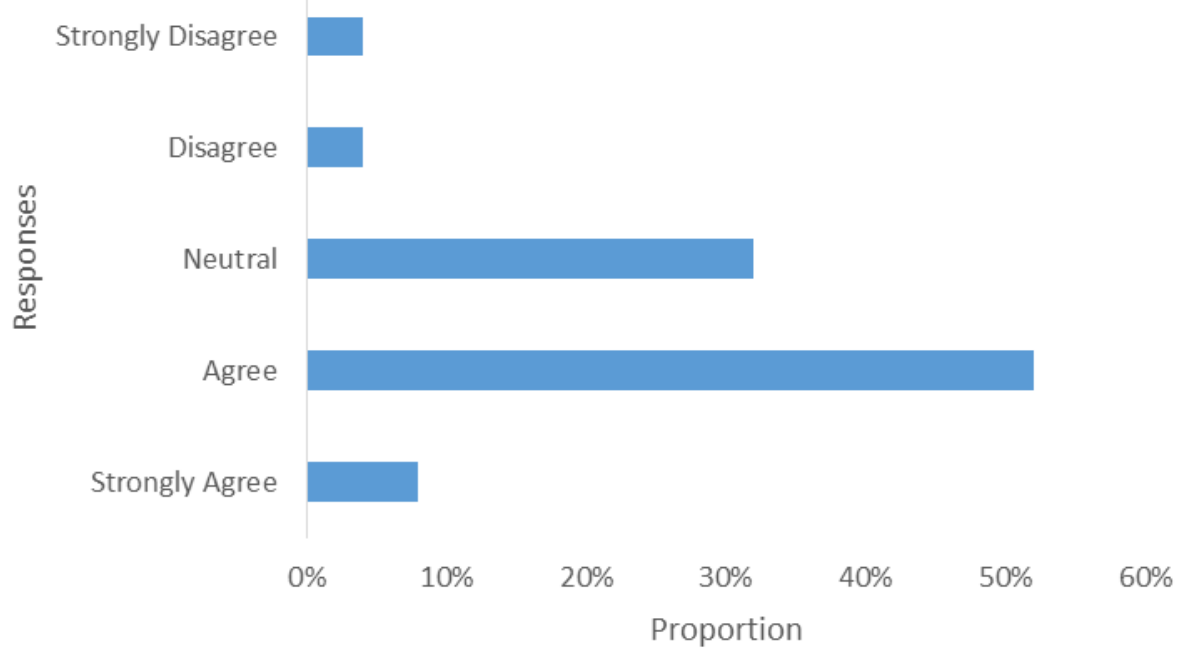

Figure 7. Students' Responses on Q8 (Discovery Learning encourages cooperation among groups of students)

Contradictive with the benefits of discovery learning that have been acknowledged by the majority of students, the proportion of students who agreed with the statement that says 'discovery learning is more interesting than conventional lecturing method' is slightly lower than the ones who thought that lecturing is more important than discovery learning (see Figure 8 and 9).

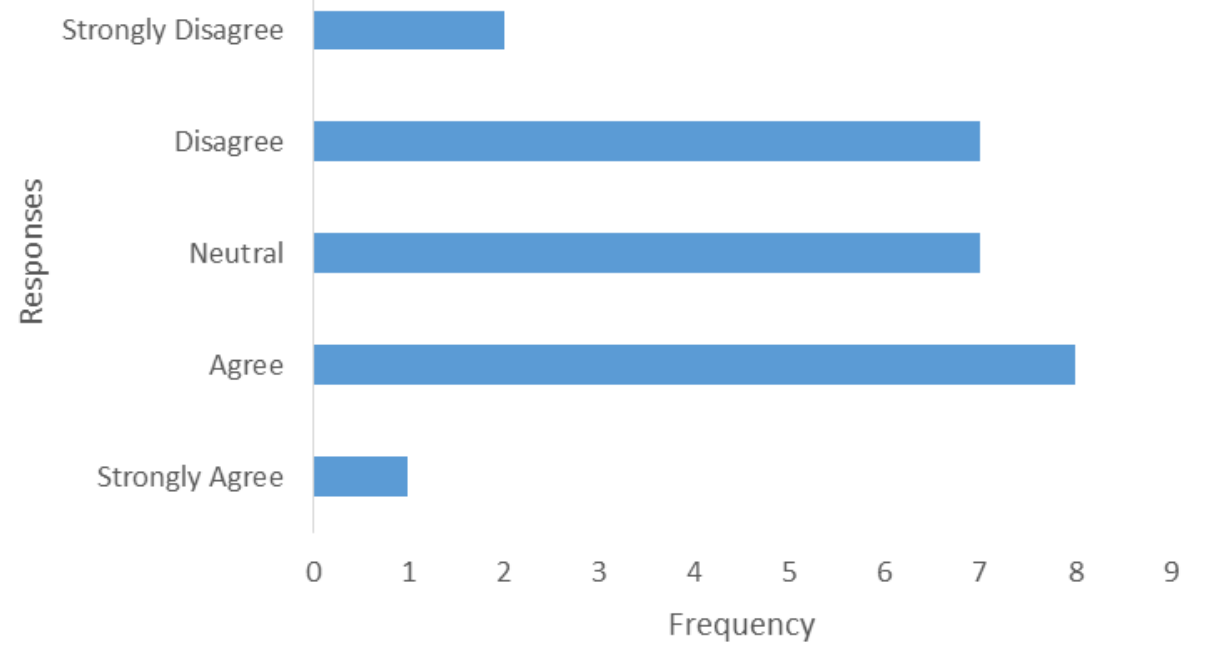

Figure 8. Frequency of Students' Responses on Q6 (Discovery Learning is more interesting than the conventional lecturing method) 


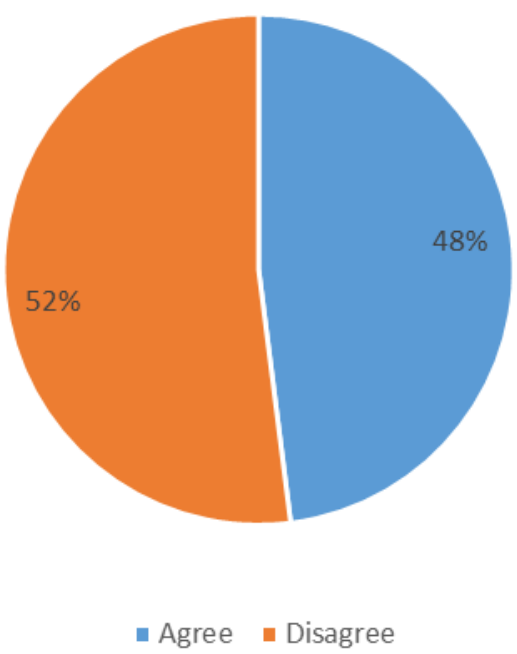

Figure 9. Proportion of Students' Responses on Q6 (Discovery Learning is more interesting than conventional lecturing method)

The last two questions in part I of the survey (Q9 and Q10) aim to find out students' opinion regarding of individual project assignment to them.

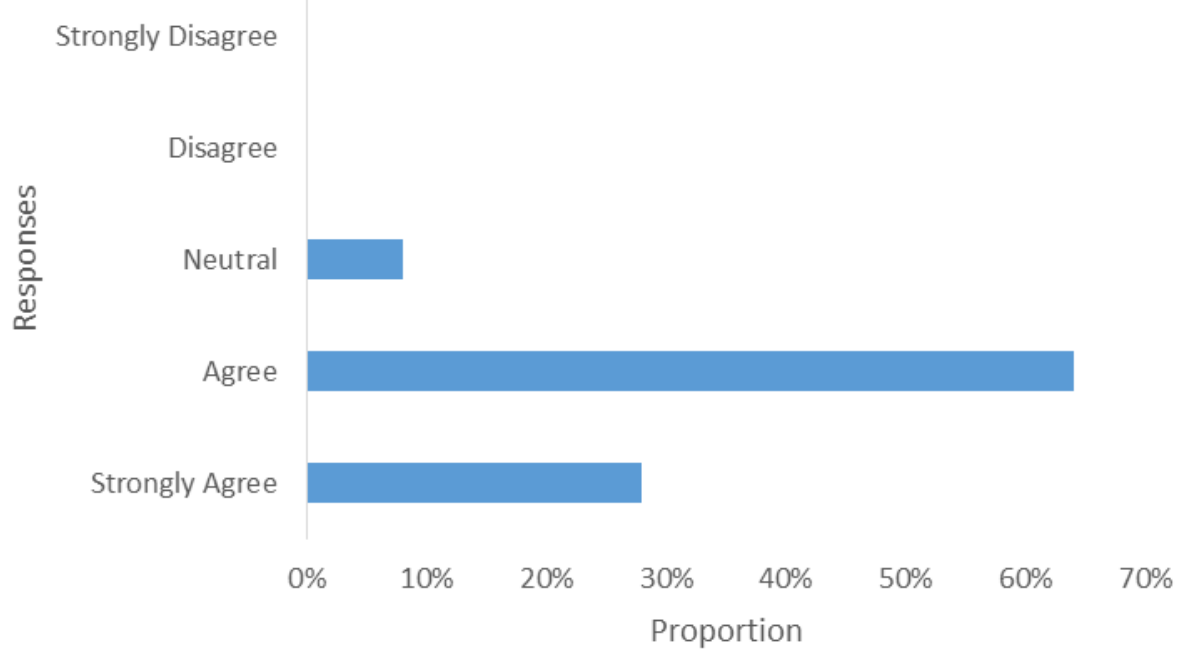

Figure 10. Proportion of Students' Responses on Q9 (Individual Project helps deepen my understanding on the topic of my interest

As reflected from Figure 10, over $90 \%$ of students agreed that doing individual project has deepen their understanding on the topic of their interest. Only $8 \%$ or two students who choose 'neutral'. However, when students were asked whether this year model of individual assignment should be continued, the responses were different from the previous question (see Figure 11). 


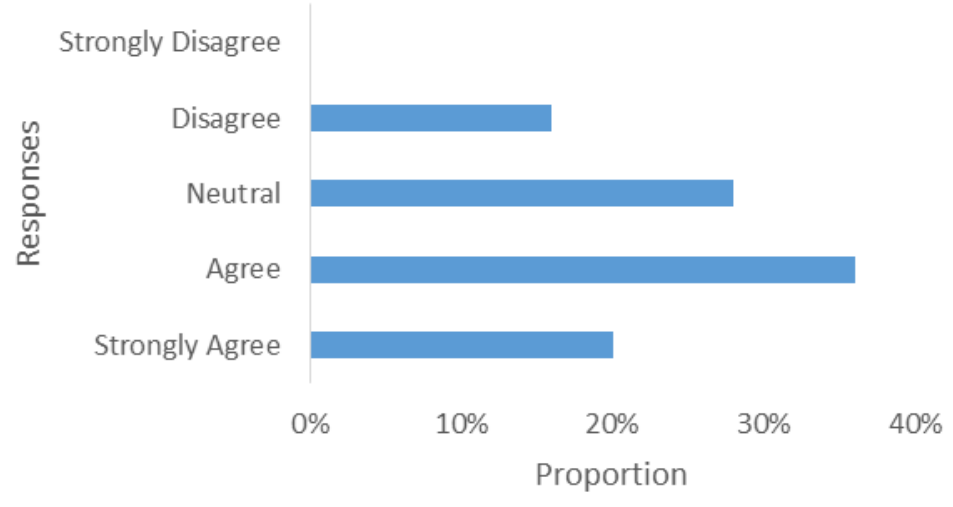

Figure 11. Proportion of Students' Responses on Q10 (The current model of individual project should be continued)

As presented in Figure 11, only 56\% of students who agreed that the individual project should be continued.

When look at students' performance under discovery learning experimentation, it seems much better compared to when the course was delivered through conventional lecturing model in 2017 (see Figure 12). As can be seen from Figure 12, the highest proportion of students' mark in 2017 was 'B minus' (33\%), then followed by 'B' (19\%). Students who obtained 'A' mark was only $7 \%$ and 'A minus' was $14 \%$. There were students who got marks ' $\mathrm{C}$ ' $+(5 \%)$, 'C' $(17 \%)$ and even ' $D$ ' (2\%).

For the 2018, however, majority of students got 'A' mark (40\%) and $20 \%$ got 'A minus'. The rest obtained $\mathrm{B}+(16 \%)$ and 'B' $(20 \%)$. None of students got 'B minus', 'C plus', 'C' or ' $\mathrm{D}$ '. There was only one student who failed the course but it was to do with plagiarism case.

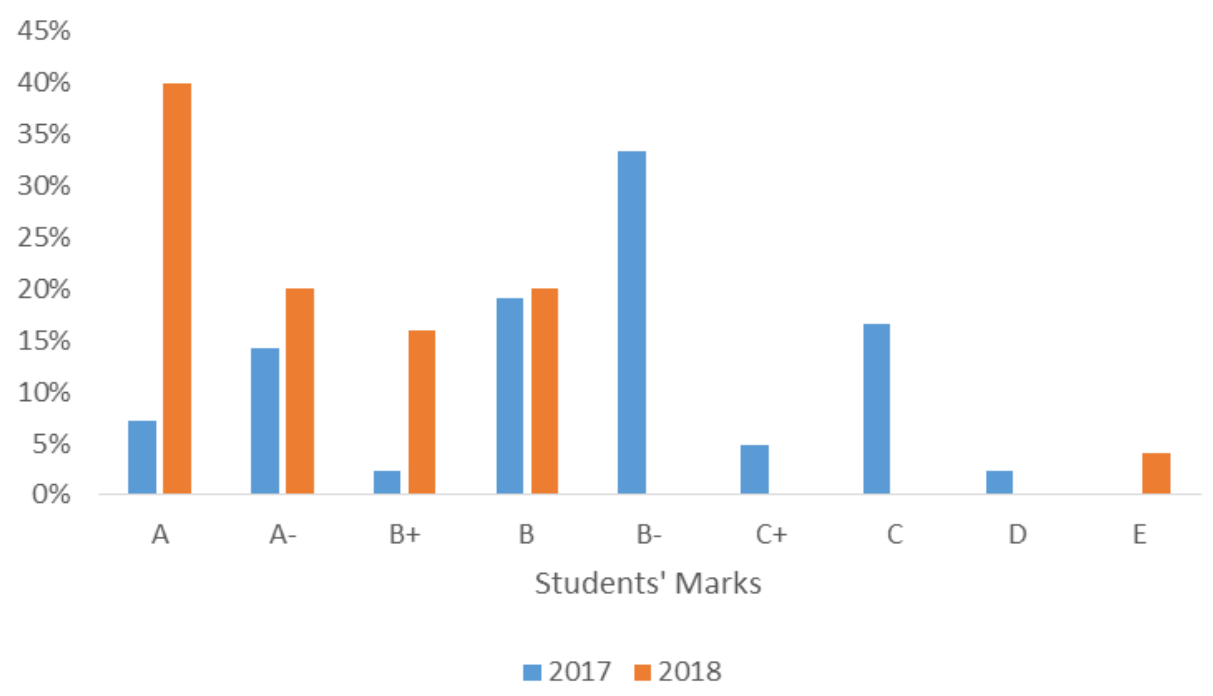

Figure 12. Students' Marks for Sharia Accounting Course (class IV/A2) for 2017 and 2018 


\section{Discussion}

The inconsistent result of the survey may suggest two things: (i) There were problems in the process of implementation (ii) The readiness of students to adopt inductive model or learning such as discovery learning needs to be revisit. It cannot be denied that the first attempt to implement any new technique must face problems and challenges. For instance, feedback in discovery learning is crucial to ensure that students obtain the correct understanding on the content being studied. The limited time left after group presentation sometimes left not much time to give feedback and clarify things to students. This problem can be improved through a better time management in the class. Adoption of discovery learning actually required highly experienced instructors [9]. This was probably what missed when considering the adoption of the technique in the first place.

A part from various problems found during the implementation, readiness of students to adopt the inductive learning approach was different from expected. Despites the recognition on the benefits of the discovery learning technique, many students in fact, still preferred the conventional lecturing method. As described in Section 4, more students preferred for the technique to be replaced with the conventional lecturing. The arguments put forward by students are logical as reflected from a quote below:

The technique is not suitable with the nature of the course that involves concepts and principles of sharia which are better explained by lecturer to avoid misunderstanding and misleading (S18).

The quote above is a response to an open-ended question about the weakness of the discovery learning that was adopted in class IV/A2 for sharia accounting course. Another response also indicates that there is a need to change the mind-set of the students that instructor is no longer the only source of knowledge:

I am not sure with the accuracy of information or knowledge given by my fellow students. It will be not the same when the information and knowledge are provided by the lecturer (S15).

That response reflects that that student does not trust the quality of information or knowledge if it comes from merely a fellow student instead of lecturer. This implies that students still expect for the lecturer to play an old role - the only source of knowledge.

The lack of students' readiness is also reflected from complain of many students regarding the difficulty to understand sources written in English. In discovery learning, students are free to explore materials as much as they can. Unfortunately, for sharia accounting subject, the availability of sources written in Bahasa is rather still very limited. The fact that quite many students complained about sources written in English, it shows lack of readiness of students to adopt the discovery learning. Finally, students did not like the idea that they have to do most of the work while lecturer seems to do nothing. 


\section{Conclusions}

Given its' specific characteristics, sharia accounting course that requires understanding about basic concepts and principles of sharia - pure discovery learning cannot be implemented. Basic concepts and principles of sharia might be better taught by lecturer to ensure that students obtain the correct understanding of the principles as many students recommended in the survey. Principles of discovery learning still can be continued because its benefits have been proven. What needs to be one is to improve student readiness to adopt more inductive learning. Supplementation of discovery learning with case study-based learning will help improve students' skills related to technical aspects of sharia accounting that involve calculations.

\section{References}

[1] Castronova, A. J. (n.y) Discovery Learning for the 21st Century: What is it and how does it compare to traditional learning in effectiveness in the 21st Century?

[2] Wright B, G (2011) Student-Centered Learning in Higher Education International Journal of Teaching and Learning in Higher Education. 2011, Volume 23, Number 3, 92-97

[3] Ramsden, P. 2003. Learning to teach in higher Education. 2nd ed. London: Taylor and Francis

[4] Norman, G.R., and H.G. Schmidt. 1992. The psychological basis of problem-based learning: A review of the evidence. Academic Medicine 67 (9): 557-65

[5] Coles, C.R. 1985 Differences between conventional and problem-based curricula in their students' approaches to studying. Medical Education 19(4): 308-09

[6] Bicknell-Holmes, T. \& Hoffman, P. S. (2000). Elicit, engage, experience, explore: Discovery learning in library instruction. Reference Services Review. 28(4), 313-322

[7] Bonwell, C. C. (1998). Active Learning: Energizing the Classroom. Green Mountain Falls, CO: Active Learning Workshops

[8] Mosca, J. \& Howard, L. (1997). Grounded learning: Breathing live into business education. Journal of Education for Business. 73, 90-93

[9] Prince, M. and Felder, R (2001) the Many Faces of Inductive Teaching and Learning. Journal of College Science Teaching, Vol. 36, No. 5. 